\title{
Supporting Information For: Orbital-Optimized MP3 and MP2.5 with Density-Fitting and Cholesky Decomposition Approximations
}

\author{
Uğur Bozkaya* \\ Department of Chemistry, Hacettepe University, Ankara 06800, Turkey \\ E-mail: ugrbzky@gmail.com
}

*To whom correspondence should be addressed 


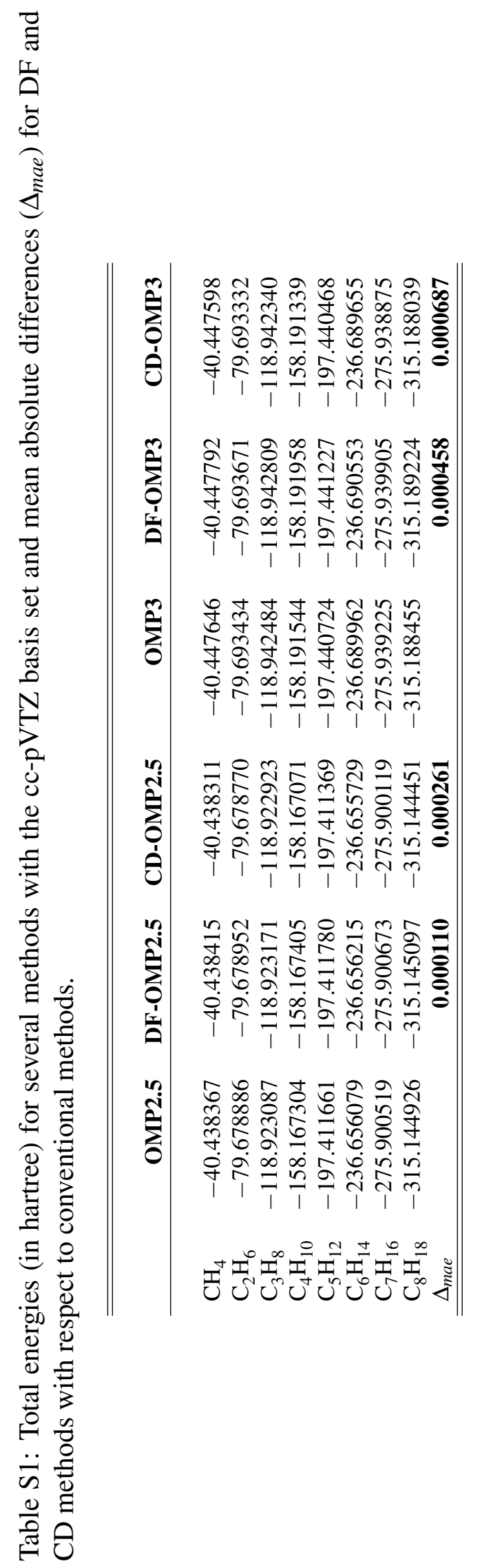




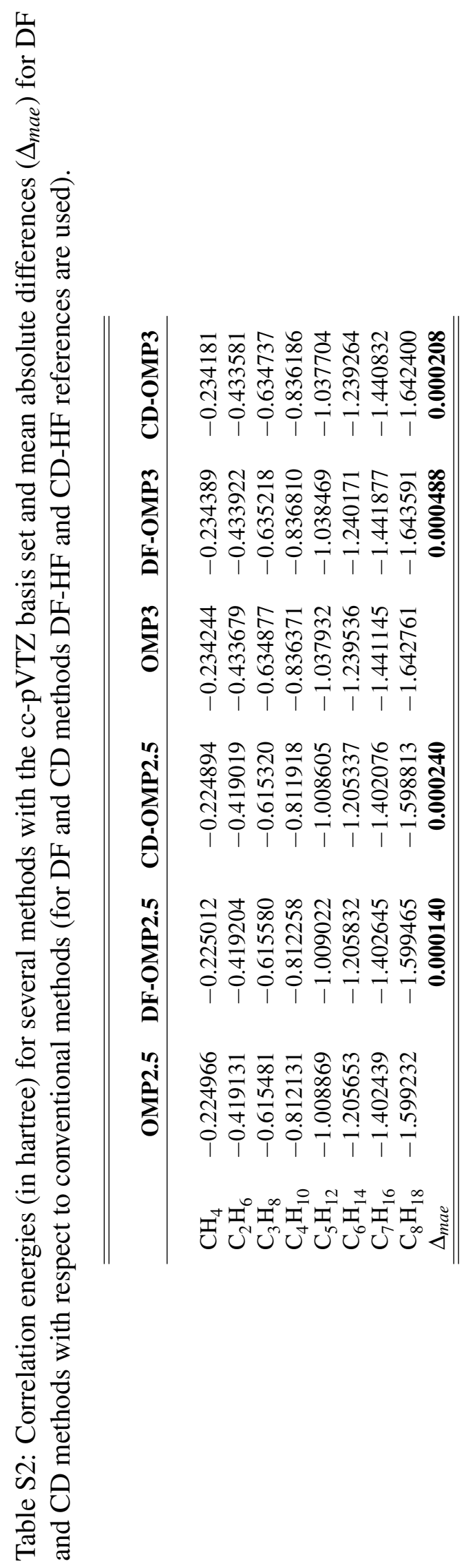




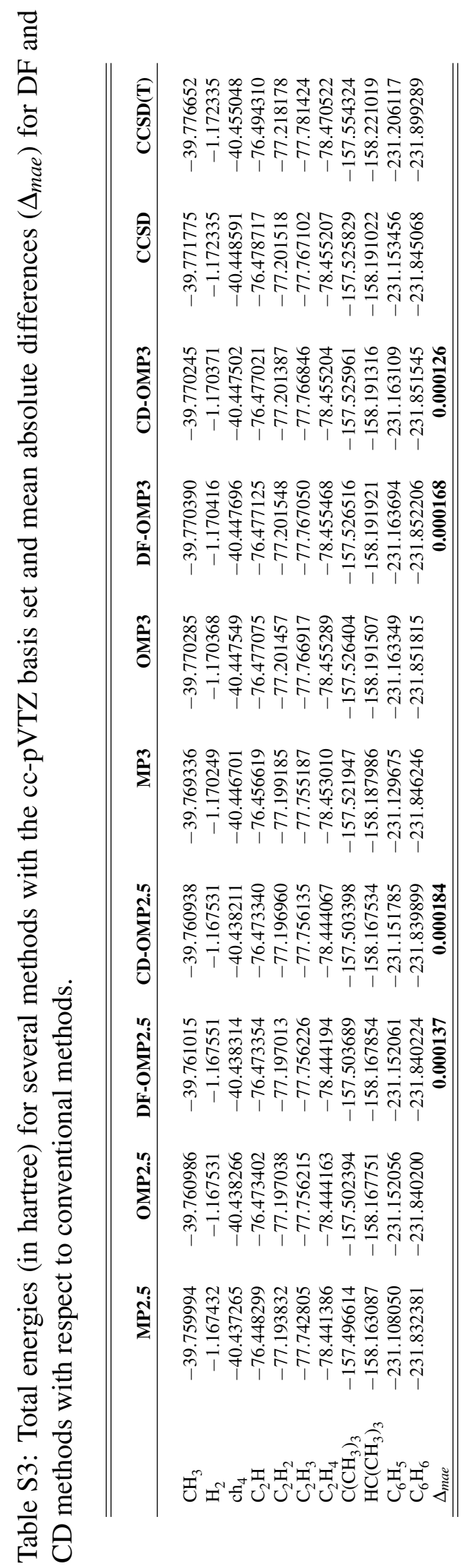




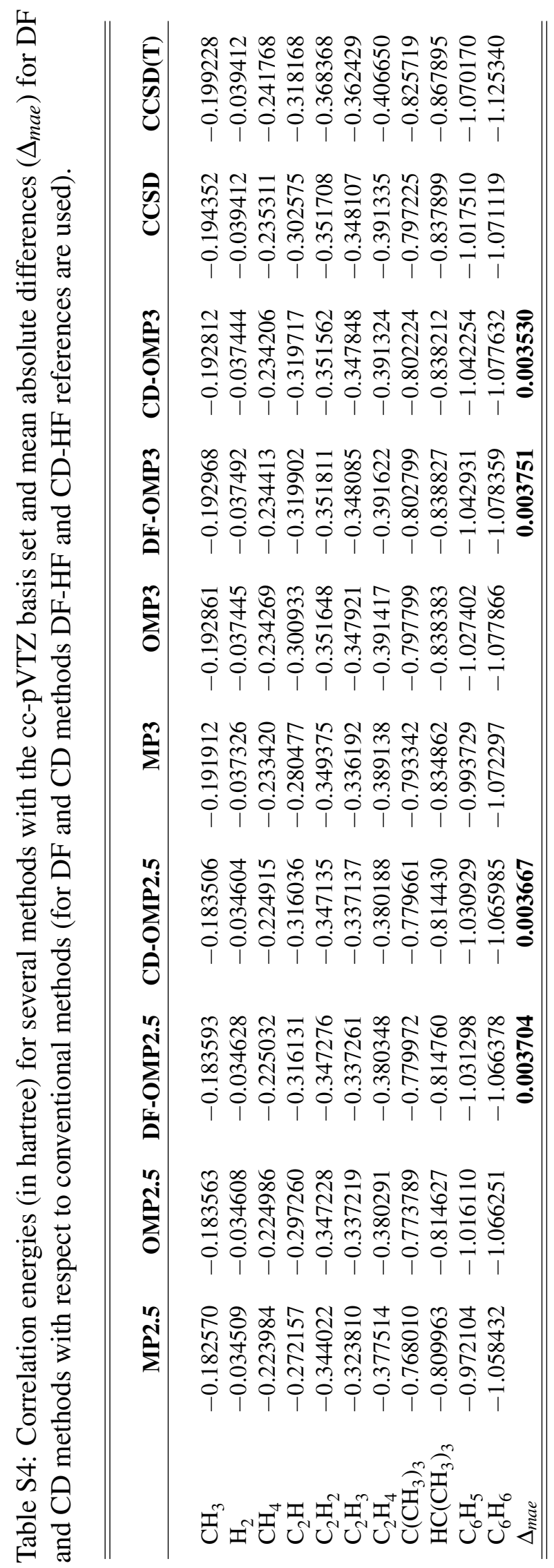




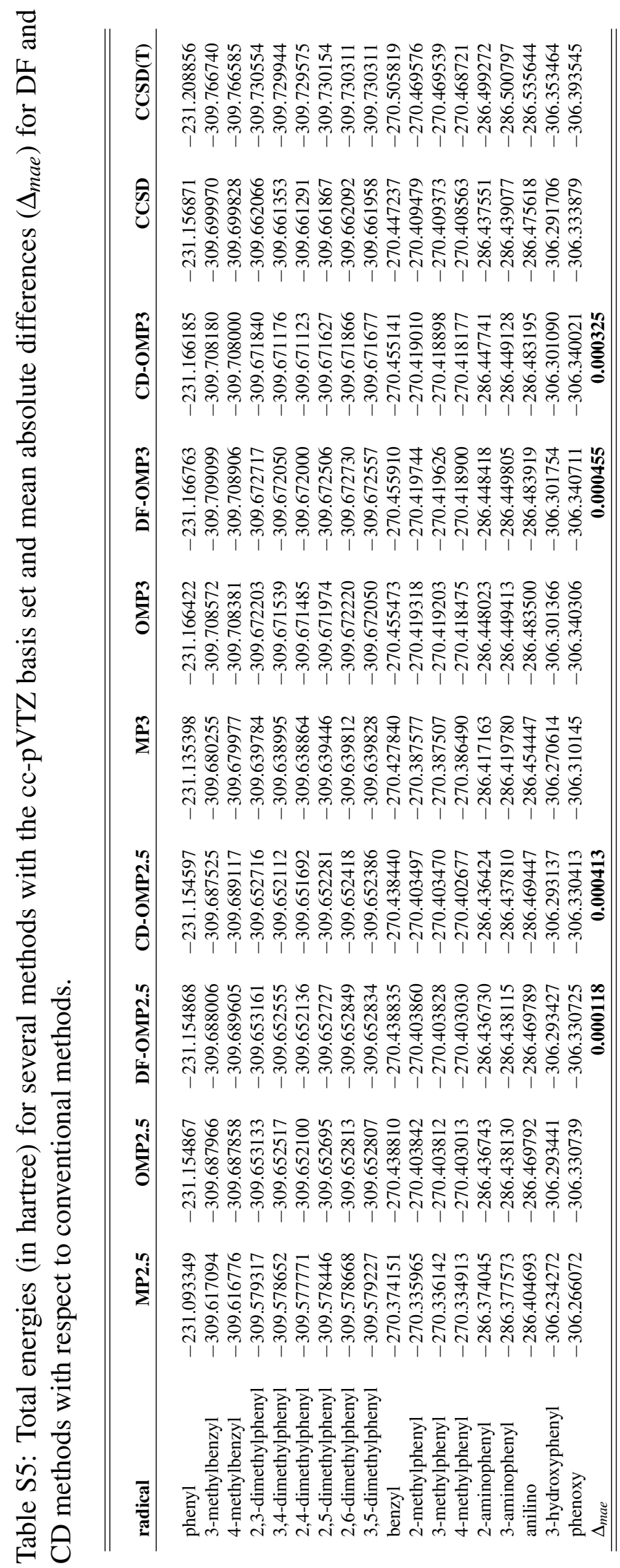




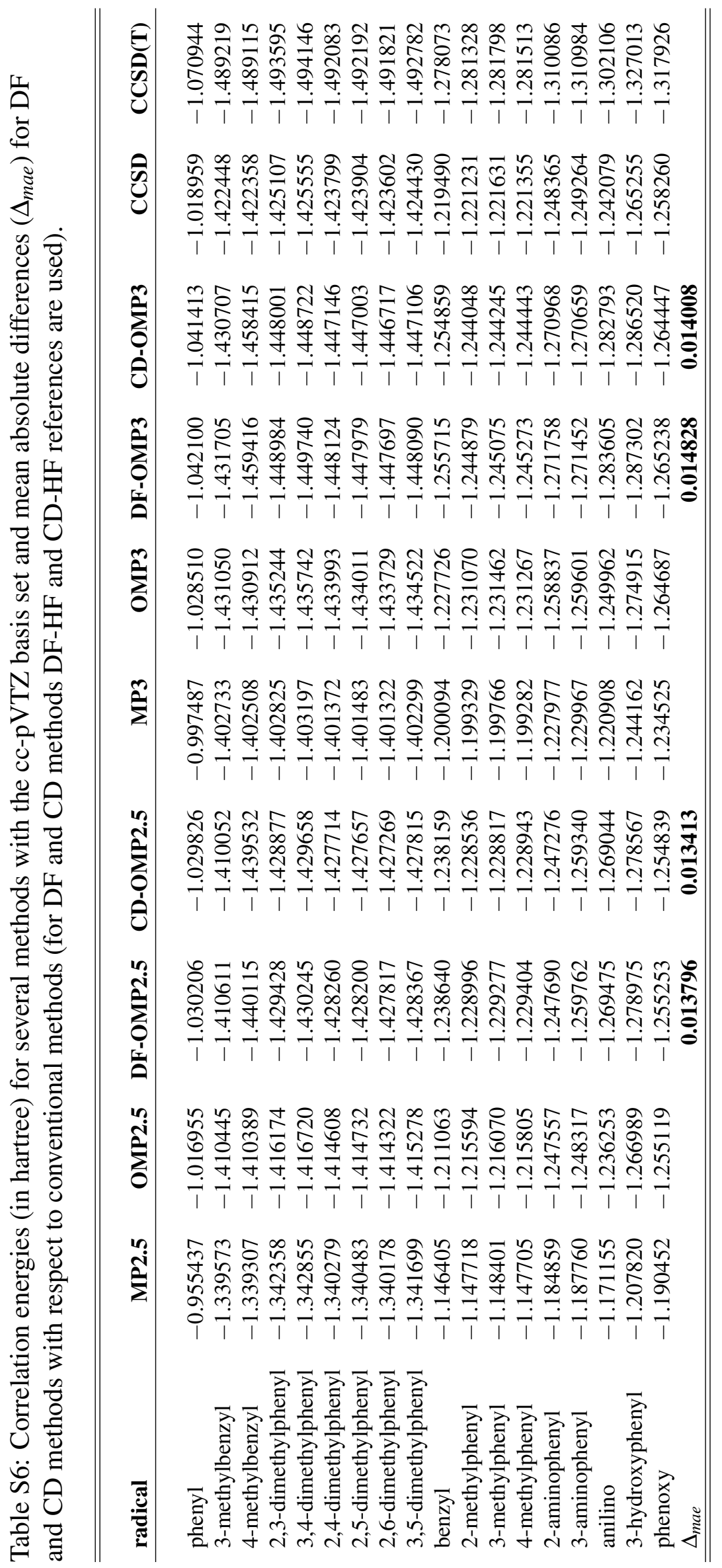




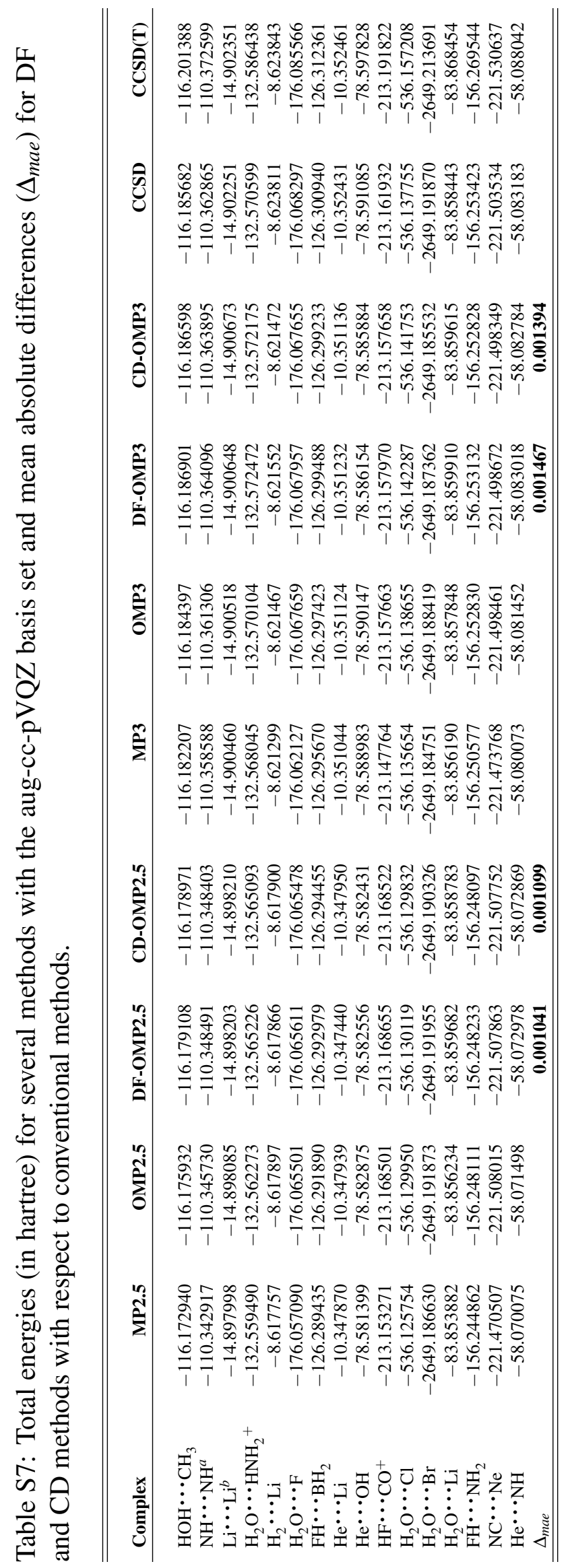




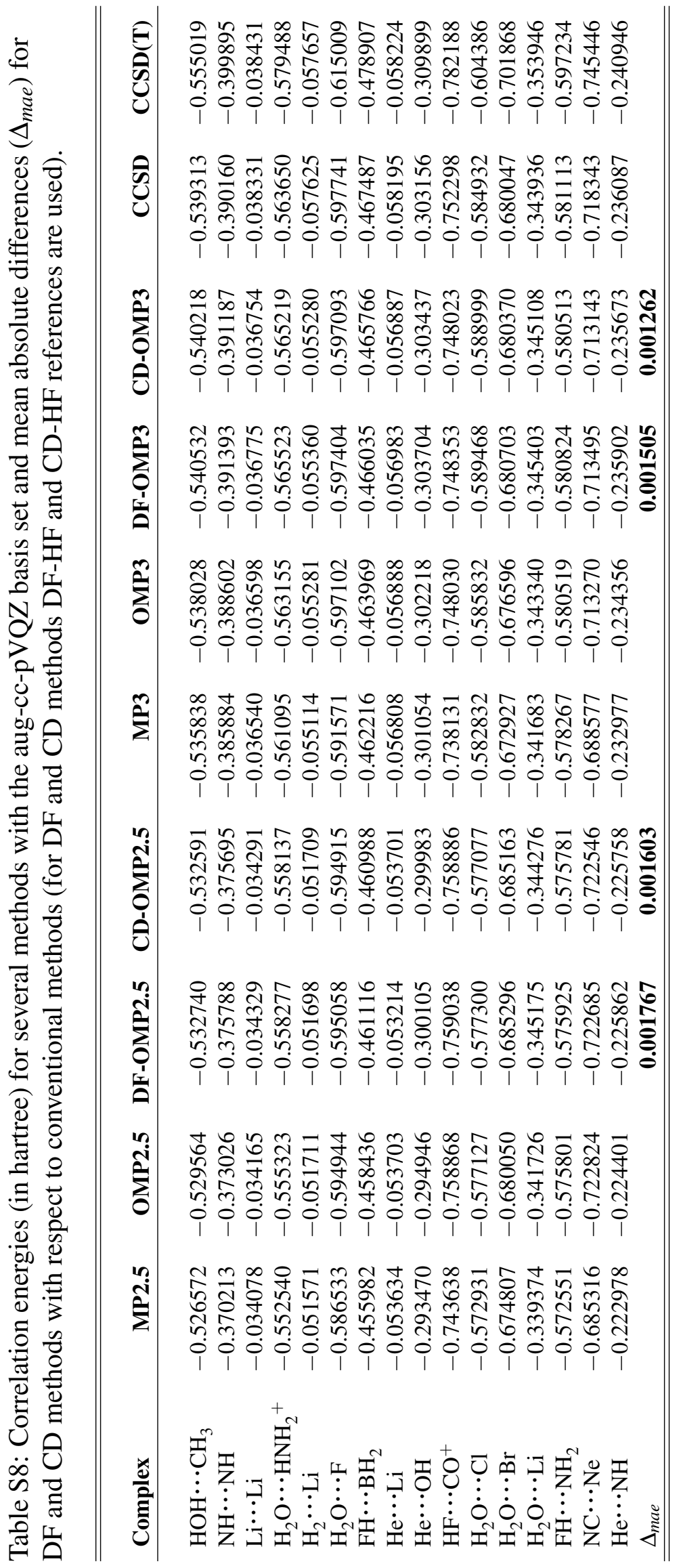

